\title{
Inhibitors in Patients with Congenital Bleeding Disorders Other Than Hemophilia
}

\author{
Massimo Franchini, MD ${ }^{1,2}$ Giuseppe Marano, MD ${ }^{1} \quad$ Carlo Mengoli, MD ${ }^{1}$ Vanessa Piccinini, MD \\ Simonetta Pupella, MD ${ }^{1}$ Stefania Vaglio, MD ${ }^{1,3}$ Giancarlo Maria Liumbruno, MD ${ }^{1}$
}

${ }^{1}$ Italian National Blood Centre, National Institute of Health, Rome, Italy
2 Department of Hematology and Transfusion Medicine,
Carlo Poma Hospital, Mantua, Italy
${ }^{3}$ Department of Clinical and Molecular Medicine, Sapienza University
of Rome, Rome, Italy

Semin Thromb Hemost

\author{
Address for correspondence Massimo Franchini, MD, Department of \\ Hematology and Transfusion Medicine, Carlo Poma Hospital, \\ Strada Lago Paiolo 10, 46100 Mantova, Italy \\ (e-mail: massimo.franchini@asst-mantova.it).
}

\begin{abstract}
Keywords

- inherited bleeding disorders

- alloantibodies

- congenital

- inhibitors

The most worrying complication of replacement therapy for severe hemophilia A and B is currently the occurrence of inhibitory alloantibodies against infused factor VIII and factor IX, respectively. Inhibitors compromise the management of hemorrhage in affected patients, with a considerable increase in complications, disability, and costs. While these alloantibodies have been extensively studied in the past years in hemophilia $A$ and $B$, those occurring in patients with other inherited bleeding disorders are less well characterized and still poorly understood, mostly due to the rarity of these hemorrhagic conditions. This narrative review will deal with inhibitors arising in patients with inherited bleeding disorders other than "classical" hemophilia, focusing in particular on those developing in patients with congenital deficiency of coagulation factor V, factor VII, factor XI, and factor XIII.
\end{abstract}

The most serious complication of treatment with coagulation factor concentrates in patients with congenital hemophilia is development of alloantibodies against the deficient coagulation factor (F), namely, VIII (FVIII; hemophilia A) or IX (FIX; hemophilia B). ${ }^{1-5}$ Indeed inhibitory alloantibodies, which develop in up to one-third of previously untreated patients with severe hemophilia $A$ and up to 5 to $6 \%$ of patients with severe hemophilia $B$, neutralize the coagulant effect of factor replacement therapy, therefore requiring a shift toward treatments based on FVIII- and FIX-bypassing agents. ${ }^{6-8}$ As a consequence, inhibitors preclude the access of persons with hemophilia to safe and effective standards of care, predisposing them to increased risk of morbidity and permanent disability which, ultimately, negatively influences their quality of life. ${ }^{7}$ The management of hemophilia A patients with inhibitors is particularly challenging for physicians operating at hemophilia treatment centers (HTCs), as they are frequently forced to make critical decisions based on their own experi-

Issue Theme Alloantibodies and Congenital Bleeding Disorders:

New Insights in the Pathogenesis and Management; Guest Editors: Antonio Coppola, MD, Massimo Franchini, MD, Cristina Santoro, MD, PhD, and Annarita Tagliaferri, MD.

ence rather than on evidence-based data. ${ }^{9}$ Due to the heavy social, health, and economic burden of inhibitors, ${ }^{3}$ it is not surprising that several investigators have devoted their research in the last decade on understanding the pathogenic mechanisms of inhibitors to predict and, possibly, prevent their development. ${ }^{9}$ However, while such investigation has been focused mainly on patients with hemophilia $A$ and $B$, little is known pertaining to the inhibitors occurring in persons with the rarer congenital bleeding disorders due to defects of the other clotting factors. In this narrative review, we summarize the current knowledge on alloantibodies complicating replacement treatment in patients with inherited deficiency of coagulation FV, FVII, FXI, and FXIII. Alloantibodies occurring against von Willebrand factor in patients with von Willebrand disease and patients with Glanzmann's thrombasthenia and other inherited platelet disorders will not be discussed here, as these are the subjects of two other reviews in this issue of the journal. ${ }^{10,11}$

Copyright $\odot$ by Thieme Medical Publishers, Inc., 333 Seventh Avenue, New York, NY 10001, USA. Tel: +1(212) 584-4662.
DOI https://doi.org/ 10.1055/s-0037-1607441. ISSN 0094-6176. 


\section{Search Methods}

We reviewed the medical literature for published studies on alloantibodies in patients with inherited bleeding disorders other than hemophilia A or hemophilia B. The MEDLINE electronic database was searched without temporal limits using English language restriction. The Medical Subject Heading and key words used were: "alloantibodies," "inhibitors," "inherited," “congenital," "bleeding disorders," "hemorrhagic disorders," "coagulation factors deficiency," “factor V (FV)," "factor XI (FXI)," "factor VII (FVII)," and "factor XIII (FXIII)." We also screened the reference lists of most relevant review articles for further studies not captured in our initial literature search. Search terms were also applied to abstracts from the latest international congresses on hemostasis and thrombosis and hematology.

\section{Alloantibodies in Congenital FV Deficiency}

\section{Characteristics of Congenital FV Deficiency}

FV is a 249 kDa glycoprotein encoded by F5 gene located on chromosome 1 and synthesized by megakaryocytes and hepatocytes. ${ }^{12}$ Approximately $20 \%$ of circulating FV is contained in platelets. ${ }^{13}$ Once activated by thrombin, FVa acts as a cofactor for FXa in the conversion of prothrombin to thrombin. ${ }^{14}$ Notably, as FV also downregulates FVIII activity, an FV deficiency may result in a thrombotic tendency. ${ }^{15,16}$ Most cases of FV deficiency are characterized by the concomitant deficiency of FV activity and antigen levels (type I deficiency), while a quarter of them have normal antigen levels, suggesting the presence of a dysfunctional protein (type II deficiency). ${ }^{12}$ FV deficiency is inherited in an autosomal recessive manner and has an estimated prevalence of approximately $1: 1,000,000 \cdot{ }^{17-19}$ The first causative mutation in the $F 5$ gene leading to a severe FV deficiency was discovered nearly 20 years ago ${ }^{20}$ and there are currently more than 200 cases described so far with more than 100 DNA alterations reported, including nonsense and missense mutations, insertions, deletions, and splice-site mutations. ${ }^{21}$ Two-thirds of all mutations causing FV deficiency are nonsense mutations in the FV gene. One-third of mutations causing FV deficiency introduce premature stop codons in the FV gene, either as nonsense mutations or as small out-of-frame insertions or deletions. Many new missense mutations, clustered in the $\mathrm{A}$ and $\mathrm{C}$ domains, have been described in recent years and now represent nearly $50 \%$ of all reported mutations. In most cases, these mutations affect secretion of $\mathrm{FV}$, thus substantially reducing antigen levels (type I deficiency). ${ }^{21}$ The fact that most patients carry a unique mutation which is not found in other FV-deficient patients confirms the remarkable allelic heterogeneity of this disease. ${ }^{22}$ The initial identification of congenital FV deficiency may be based on the demonstration of the prolongation of both prothrombin time (PT) and activated partial thromboplastin time (aPTT), and the diagnosis by identification of reduced FV activity, usually determined by modified one-stage PT-based clotting assays. To distinguish qualitative from quantitative FV deficiency, a plasma FV antigen determined by immunoassay is required. ${ }^{23}$ Congenital FV deficiency can be distinguished from acquired FV deficiency, in most cases due to FV autoantibodies occurring after exposure to bovine FV present in topical thrombin, ${ }^{24}$ by noncorrection in PT and aPTT mixing studies in subjects without previous bleeding history.

Frequent symptoms in patients with FV deficiency are epistaxis and menorrhagia, which occur in approximately $50 \%$ of cases. Other, less common symptoms, include hemarthroses and hematomas, which occur in approximately $25 \%$ of patients, whereas life-threatening episodes in the central nervous system and gastrointestinal tract are rare (6\%). ${ }^{25-27}$

Pertaining to the treatment, there is no FV concentrate available, and FV is not present in significant amount in cryoprecipitate or prothrombin complex concentrates. ${ }^{28}$ Thus, replacement therapy of FV is only achieved through fresh frozen plasma, preferably virus inactivated. ${ }^{29-34}$ Due to their relative content of FV, platelet transfusions have also been successfully used for the management of FV-deficient patients. ${ }^{35}$

\section{Anti-FV Alloantibodies}

Development of alloantibodies against infused FV is a potential complication of replacement therapy with fresh frozen plasma in patients with severe congenital FV deficiency. ${ }^{28}$ Although very few cases have been reported in the literature so far, ${ }^{36-41}$ the incidence of this adverse event could be underestimated, especially if low-titer transient inhibitors are considered. ${ }^{42}$ For instance, Fratantoni and colleagues ${ }^{36}$ described an 8 -year-old girl with hereditary FV deficiency who developed an IgG class anti-FV alloantibody after treatment with fresh frozen plasma for several years. It is, however, possible that the FV inhibitor developed earlier, during the first few plasma transfusions, because of a noted initial partial correction of prolonged coagulation profile after fresh frozen plasma transfusions. Subsequently, as the inhibitor titer increased, more frequent plasma transfusions failed to improve the prolonged PT and aPTT. Similarly, Mazzucconi and colleagues ${ }^{37}$ reported the case of a female patient with severe congenital FV deficiency who became refractory to plasma infusion due to the development of a low-titer anti-FV antibody. Salooja and colleagues ${ }^{38}$ reported another case of neonatal intracranial hemorrhage associated with severe congenital FV deficiency complicated by an FV inhibitor ( 0.6 Bethesda units [BU]), successfully managed by solvent detergent-treated fresh frozen plasma and platelet concentrate infusion. Lee and colleagues ${ }^{39}$ reported the dramatic case of an 18-day-old Indian infant with severe FV deficiency and FV inhibitor (2.4 BU) with intracranial hemorrhage. Repeated transfusions of fresh frozen plasma and platelet concentrates, administrations of immunosuppressive therapy (prednisolone and cyclophosphamide), and intravenous immunoglobulin (IVIG) failed to normalize the coagulation profiles. Exchange transfusion followed up by administrations of activated prothrombin complex and transfusions of fresh frozen plasma and platelet concentrates caused a temporary normalization of coagulation profile, enabling an insertion of a ventriculoperitoneal shunt for progressive hydrocephalus. The treatment was, however, complicated by thrombosis of the left brachial artery and the child finally died from another episode of intracranial hemorrhage 10 days thereafter. Divanon and colleagues ${ }^{40}$ reported the case of a 19 -year-old man with severe 
congenital FV deficiency and a high-titer (6 BU) inhibitor who was treated with single donor leukocyte-depleted platelet concentrate with a consequent anamnestic response (FV inhibitor rose up to $30 \mathrm{BU}$ ). Thus, the patient was successfully treated with recombinant activated factor VII (rFVIIa, bolus injections of $80 \mu \mathrm{g} / \mathrm{kg}$ at 3 hourly intervals on the first day, at 4 hourly intervals on the second day and then two daily boluses). Finally, Perez Botero and colleagues ${ }^{41}$ described the case of a 67-year-old man with congenital FV deficiency and a high-titer FV inhibitor level with recurrent gastrointestinal bleeding due to arteriovenous malformations successfully treated with thalidomide after endoscopic, hemostatic (activated prothrombin complex concentrate), and hormonal (danazol) treatment failed. As immune tolerance induction (ITI) treatment was impracticable due to the high dose of fresh frozen plasma required, an alternative approach with high-dose corticosteroids and rituximab was attempted, resulting in inhibitor eradication.

In summary, the data available on the characteristics of alloantibodies against infused FV in congenital FV deficiency are scanty (-Table $\mathbf{1}$ ), and most information regarding their management are derived from reports of acquired FV inhibitors. ${ }^{43-45}$ Thus, for inhibitor eradication, various immunosuppressive agent-based protocols have been suggested. ${ }^{45}$ Pertaining to the treatment of bleeding, a large volume of fresh frozen plasma, necessary to overcome the inhibitor and produce an effective hemostatic effect, and platelet concentrates represent the mainstay of the treatment of bleeding in these complicated cases. In particular, transfusion of platelet concentrates should be considered as initial therapy, considering that FV in platelets, unlike that circulating in plasma, is protected from the neutralization of the antibody, being delivered directly to the site of injury. ${ }^{46,47}$ Also, the transfusion of platelets decreases the risk of circulatory overload associated with the transfusion of the large volume of plasma. In patients, refractory to repeated platelet transfusions, the administration of rFVIIa could be beneficial. ${ }^{40}$ The main advantages of this recombinant hemostatic agent in such clinical setting include the efficacy being independent of the inhibitor titer and the lack of anamnestic response. In patients with a life-threatening bleeding tendency, an immediate reduction of the FV inhibitor titer by immunoadsorption or plasmapheresis with subsequent administration of fresh frozen plasma with or without platelet concentrates might be the best therapeutic approach.

\section{Alloantibodies in Congenital FVII Deficiency}

\section{Characteristics of Congenital FVII Deficiency}

Factor VII is a $50 \mathrm{kDa}$ vitamin K-dependent glycoprotein that circulates in plasma in two forms ( $99 \%$ as a single chain inactive form and $1 \%$ as an active two-chain form). FVII, encoded by the F7 gene located on chromosome 13, plays a fundamental role in the initiation of coagulation through its interaction with tissue factor. ${ }^{48,49}$ FVII deficiency is inherited with an autosomal recessive pattern (estimated prevalence $1: 500,000) .{ }^{49} \mathrm{Circu}-$ lating levels of FVII coagulant activity (FVII:C) and FVII antigen (FVII:Ag) are influenced by several genetic and nongenetic factors (age, sex, cholesterol, and triglyceride levels), and it is also well known that FVII polymorphisms modulate FVII levels. ${ }^{50}$ Most patients have concomitantly low levels of FVII: C and FVII:Ag (type 1), but other cases are characterized by normal or moderately low levels of FVII:Ag and much lower levels of FVII:C(type 2). ${ }^{51}$ The molecular basis of FVII deficiency

Table 1 Main characteristics and management of alloantibodies in congenital FV, FXI, and FXIII deficiencies (data derived from literature analysis)

\begin{tabular}{|l|l|l|l|l|}
\hline Alloantibody & $\begin{array}{l}\text { Congenital FV } \\
\text { deficiency }\end{array}$ & $\begin{array}{l}\text { Congenital FVII } \\
\text { deficiency }\end{array}$ & $\begin{array}{l}\text { Congenital FXI } \\
\text { deficiency }\end{array}$ & $\begin{array}{l}\text { Congenital FXIII } \\
\text { deficiency }\end{array}$ \\
\hline Class & IgG & IgG & IgG & $\begin{array}{l}\text { IgG, most frequently } \\
\text { directed against FXIII-A } \\
\text { subunit }\end{array}$ \\
\hline Anaphylaxis & No & No & No & No \\
\hline Titer & $\begin{array}{l}\text { Reported cases of low } \\
\text { and high inhibitor titer. } \\
\text { Anamnestic response } \\
\text { following FFP }\end{array}$ & $\begin{array}{l}\text { Reported cases of low } \\
\text { and high inhibitor titer. } \\
\text { Anamnestic response } \\
\text { following rFVIla }\end{array}$ & $\begin{array}{l}\text { Reported cases of low } \\
\text { and high inhibitor titer. } \\
\text { Anamnestic response } \\
\text { following FXI } \\
\text { concentrate }\end{array}$ & $\begin{array}{l}\text { NR. Anamnestic response } \\
\text { following FXIII } \\
\text { concentrate }\end{array}$ \\
\hline Management & $\begin{array}{l}\text { Inhibitor eradication: } \\
\text { immunosuppressive } \\
\text { agents (steroids, } \\
\text { cyclophosphamide) } \\
\text { Treatment of bleeding: } \\
\text { FFP, platelet } \\
\text { concentrates, rFVIla, } \\
\text { immunoadsorption, } \\
\text { plasmapheresis }\end{array}$ & $\begin{array}{l}\text { Inhibitor eradication: } \\
\text { immunosuppressive } \\
\text { agents (steroids, } \\
\text { cyclophosphamide, } \\
\text { azathioprine, } \\
\text { immunoglobulin) } \\
\text { Treatment of bleeding: } \\
\text { rFVIla }\end{array}$ & $\begin{array}{l}\text { Inhibitor eradication: } \\
\text { immunosuppressive } \\
\text { agents (steroids, } \\
\text { cyclophosphamide) } \\
\text { Treatment of bleeding: } \\
\text { FXI concentrate (low } \\
\text { inhibitor titer), rFVIla }\end{array}$ & $\begin{array}{l}\text { Inhibitor eradication: ITI } \\
\text { (Malmö protocol) } \\
\text { Treatment of bleeding: } \\
\text { FXIII concentrate }\end{array}$ \\
\hline
\end{tabular}

Abbreviations: FFP, fresh frozen plasma; FV, factor V; FVII, factor VII; FXI, factor XI; FXIII, factor XIII; ITI, immune tolerance induction; NR, not reported; rFVIla, recombinant activated factor VII. 
is more extensively characterized than those of other defects, perhaps due to the relatively high frequency of this defect and small size of the gene. ${ }^{52}$ To date, more than 130 mutations distributed throughout all the exons have been described, with a considerable proportion of mutations located on exon 8 , which codes for the catalytic domain of FVII. ${ }^{53-56}$ Missense mutations are the most frequent (70-80\%), splicing-site changes are also well represented, while nonsense mutations and small deletions are rare. ${ }^{52}$ The severely deficient cases are either homozygous or double heterozygous for mutations that disrupt expression of the protein (i.e., deletions and insertions), resulting in FVII:C levels usually $<1 \%$ of normal. Individuals with a mild/moderate clinical phenotype are homozygous or doubly heterozygous for missense mutations. ${ }^{53}$ The identification of FVII deficiency may be based on a prolonged PT with normal aPTT, and diagnosis confirmed by reduced FVII:C by modified one-stage PT-based clotting assay. Measurement of plasma FVII:Ag by immunoassay is necessary to distinguish qualitative from quantitative FVII deficiency. ${ }^{30}$

The severity of symptoms of FVII deficiency is quite variable and reported to be poorly correlated with plasma levels. Some patients with severe deficiency do not bleed after major challenges of hemostasis. However, recent studies highlight that the most severe bleeding symptoms are reported in patients with FVII:C below $10 \%$ and that age and bleeding pattern at diagnosis may predict the bleeding tendency in such patients. ${ }^{49,57,58}$ Life- or limb-endangering bleeding manifestations are relatively rare, the most frequent symptoms being epistaxis and menorrhagia. ${ }^{59}$ The high incidence of central nervous system bleeding (16\%) reported by Ragni and colleagues $^{48}$ in a series of 75 patients affected by FVII deficiency, was not confirmed by two subsequent studies. ${ }^{53,60}$ Thrombotic episodes (particularly venous thrombosis), have also been reported in 3 to $4 \%$ of patients with FVII deficiency, particularly in the presence of surgery and replacement treatment; however, spontaneous thrombosis may also occur. ${ }^{60,61}$

Current therapeutic options include fibrinolytic inhibitors, fresh frozen plasma, prothrombin complex concentrates, plasma-derived FVII concentrates and rFVIIa. ${ }^{30}$ However, the very short half-life of FVII makes it difficult to use fresh frozen plasma without causing volume overload. Recombinant FVIIa has to be considered the optimal replacement therapy since it can be used at a very low dose $(15-30 \mu \mathrm{g} / \mathrm{kg}){ }^{62-64}$

\section{Anti-FVII Alloantibodies}

Rarely, replacement therapy of severe inherited FVII deficiency is complicated by the occurrence of inhibitors against infused FVII. $^{30}$ Thirteen inhibitor cases have been reported so far in eight studies, following use of either plasma-derived or rFVII products. ${ }^{65-72}$ In a prospective study of 101 spontaneous or traumatic bleeds occurring in 75 patients with congenital FVII deficiency, two inhibitors were detected in two repeatedly treated patients (one post-plasma-derived FVII, one postrFVIIa). ${ }^{67}$ See and colleagues ${ }^{72}$ reported the case of FVII inhibitor development following liver transplantation in a 5-yearold girl with severe congenital FVII deficiency. Interestingly, she was responsive to rFVIIa despite the presence of the inhibitor. ${ }^{72}$ Also, successful prophylactic rFVIIa in a patient with inherited
FVII deficiency with inhibitors to FVII was reported by Tokgoz and colleagues, ${ }^{68}$ suggesting a possible weak affinity of this alloantibody to rFVIIa. By contrast, Borhany and colleagues ${ }^{71}$ reported a FVII inhibitor case who did not respond to rFVIIa therapy despite extensive immunosuppressive (methylprednisolone and cyclophosphamide) treatment. The largest experience is that by Batorova and colleagues on behalf of the STER (Seven Treatment Evaluation Registry) study group, ${ }^{70}$ who detected FVII inhibitors in $2.6 \%$ (3/115) of patients in the registry. All inhibitors were high responders, and all but one were detected in infants with a severe FVII defect and bleeding phenotype.

\section{Alloantibodies in Congenital FXI Deficiency}

\section{Characteristics of Congenital FXI Deficiency}

FXI is a dimeric serine protease mainly synthesized in the liver and encoded by the $23 \mathrm{~kb}$ long FXI gene located on chromosome $4 .{ }^{73}$ Hereditary FXI deficiency is an autosomal bleeding disorder characterized by reduced levels of FXI in plasma and typically manifests as a prolongation of the aPTT with reduced FXI activity, as determined by one-stage modified aPTT clotting assay. ${ }^{74-76}$ The prevalence of severe FXI deficiency is approximately $1: 1,000,000$, although it has been reported to be much in Ashkenazi Jews. ${ }^{77}$ Nearly 200 different mutations affecting the FXI gene have been identified so far, missense mutations representing more than $60 \%$ of all variants. ${ }^{30,78}$ Two mutations are responsible for most cases of FXI deficiency in Ashkenazi Jews, while mutations are more varied in non-Jews. ${ }^{78,79}$ The type II Jewish mutation is a stop codon in exon 5, leading to undetectable FXI levels in homozygous individuals. The type III Jewish mutation is a missense mutation in exon 9 that causes a defective secretion of the protein from cells, but some FXI is ultimately produced so that measurable levels of FXI (at $\sim 10 \%$ ) are present in these patients. Type II/III compound heterozygosity is the commonest cause of severe to moderate FXI deficiency in Ashkenazi Jews. ${ }^{80}$

In comparison with hemophilia A or B, bleeding manifestations in FXI deficiency are much less predictable, even in patients with severe deficiency. Bleeding is not related to FXI plasma levels but rather to the site of injury. Thus, the risk of bleeding is increased when at a site of injury with local high fibrinolytic activity (e.g., oral cavity after dental extraction or tonsillectomy, urogenital tract). ${ }^{81}$ Patients with severe FXI deficiency are usually mildly affected and most bleeding manifestations are injury-related. Patients with low but detectable levels of FXI are also surprisingly mild bleeders, so that in these two groups clinical phenotypes are not strikingly different. ${ }^{82}$ Women with FXI deficiency are prone to excessive bleeding during menstruation, but case series of women affected by severe FXI deficiency showed that $70 \%$ of pregnancies were uneventful, despite no prophylactic treatment. ${ }^{83,84}$

Treatment of congenital FXI deficiency is based upon the use of antifibrinolytic agents, fresh-frozen plasma, plasmaderived FXI concentrate and rFVIIa, but attention should be paid to reduce the risk of thrombotic complications (especially when FXI concentrates are employed), volume overload when 
fresh frozen plasma is used, and allergic reactions and development of inhibitors following FXI replacement therapy (see below). ${ }^{73}$ As surgery or trauma can be associated with excessive and prolonged bleeding unless adequately treated, a careful evaluation of patients with severe FXI deficiency is recommended prior to surgery, as well as meticulous planning of the procedure and of the post-surgical course. FXI has a relatively long half-life (40-70 hours), so that the infusion of 15 to $20 \mathrm{~mL} / \mathrm{kg}$ virus-inactivated fresh frozen plasma on alternate days should be sufficient to keep FIX at trough hemostatic levels of 15 to $20 \%{ }^{85}$

\section{Anti-FXI Alloantibodies}

A severe complication of replacement therapy in congenital FXI deficiency is the development of inhibitor to infused FXI. ${ }^{86,87}$ In a study conducted in 2003 by Salomon and colleagues on 188 Israeli patients with severe FXI deficiency, 7 of 21 patients (33\%) homozygous for type II mutation developed inhibitors after exposure to plasma. ${ }^{88}$ Characterization of these inhibitors revealed that they were all $\operatorname{IgG}$ alloantibodies and inhibited activation of FXI by thrombin or activated factor XII (FXIIa) and inhibited activation of FIX by exogenous FXIa. ${ }^{88}$ Patients with FXI deficiency do not bleed spontaneously. Nevertheless, FXI inhibitors may increase surgical- or trauma-related bleeding and reduce responses to FXI replacement. ${ }^{86}$ Thus, the presence of an inhibitor should be suspected (and investigated) when replacement therapy with fresh frozen plasma or FXI concentrate fails to correct a prolonged aPTT or when a patient continues to bleed despite appropriate treatment. In such cases, aPTT mixing studies and the modified Bethesda assay are helpful to detect and quantify the FXI inhibitor. ${ }^{88}$ In addition, a periodical screening for inhibitor is mandatory in patients with severe FXI deficiency due to null mutations, especially if a surgical procedure is planned. ${ }^{30}$

Pertaining to the treatment of inhibitor patients, when the titer of inhibitor is low, the use of FXI concentrate may be hemostatically sufficient, although an anamnestic response is to be expected. ${ }^{75}$ Since the first successful report by Hedner and colleagues in $1990,{ }^{89}$ several authors have reported effective hemostatic treatment of severe FXI deficiency and inhibitors using rFVIIa at doses varying between 30 and $90 \mu \mathrm{g} / \mathrm{kg}^{90-93}$ More recently, Livnat and colleagues $^{94}$ observed that relatively low concentrations of rFVIIa corrected in vitro thrombin generation in plasma from patients with severe FXI deficiency and an inhibitor. On the basis of this finding, the same authors treated three patients with severe FXI deficiency and FXI inhibitors who underwent major surgery with a single low dose of rFVIIa $(15-30 \mu \mathrm{g} / \mathrm{kg})$ and tranexamic acid and this protocol secured normal hemostasis without thrombotic adverse events. ${ }^{95}$ All in all, these data suggest that rFVIIa in patients with severe FXI deficiency and inhibitors may induce effective hemostasis at doses that are lower than those required for patients with severe hemophilia A or B and inhibitors. ${ }^{96}$ Finally, successful inhibitor eradication with immunosuppressive therapy (cyclophosphamide and steroids) has been reported by Teruya and Styler. 97

\section{Alloantibodies in Congenital FXIII Deficiency}

\section{Characteristics of Congenital FXIII Deficiency}

FXIII, also called fibrin-stabilizing factor, is the last enzyme to be activated in the blood coagulation pathway and functions to crosslink $\alpha$ - and $\gamma$-fibrin chains, resulting in a stronger clot with an increased resistance to fibrinolysis. ${ }^{98,99}$ The plasma factor consists of two catalytic A subunits (FXIII-A) and two carrier B subunits (FXIII-B). FXIII-A is synthesized in cells of bone marrow origin, while FXIII-B is produced in the liver. The corresponding genes are located on chromosome 6 and $1 .{ }^{100,101}$ Inherited FXIII deficiency is an autosomal recessive disorder with a frequency of approximately 1:2,000,000 in the general population. Routine coagulation screening tests (PT, aPTT and platelet count) are usually normal, and traditionally the diagnosis of FXIII deficiency has been established by the demonstration of increased clot solubility in a $5 \mathrm{M}$ urea or $1 \%$ monochloracetic acid solution. However, such assays may not reliably identify FXIII-deficient patients, and functional or specific immunoassay tests that measure FXIII-A and FXIII-B antigen levels have been developed. ${ }^{100,102}$ More than one hundred different mutations have been identified so far in the FXIII registry database (available at: http://www.f13-database.de, accessed March 7, 2017), with missense mutations being those most commonly reported for both genes, although the majority of such defects are identified in the A-subunit, scattered throughout the F13A gene. ${ }^{101} \mathrm{~Pa}-$ tients with severe disease characterized by low plasma levels of FXIII can have homozygous mutations or compound heterozygous mutations. $^{103}$

Individuals with FXIII deficiency have an increased tendency to bleed. ${ }^{104}$ Animal models of severe FXIII deficiency present with intrathoracic, intraperitoneal and subcutaneous hemorrhage. ${ }^{105}$ In humans, bleeding from the umbilical stump in the first few days of life is common. Intracranial hemorrhage, ecchymoses, hematomas and prolonged bleeding following trauma are also characteristic. ${ }^{106}$ Delayed wound healing was reported in approximately $30 \%$ of FXIII-deficient patients, while hemarthroses and bleeding into the muscles are less common than in hemophiliacs. ${ }^{107}$ In a study using the largest group of patients with severe FXIII deficiency (93 Iranians) the most frequent mucosal tract bleeding symptom was bleeding in the oral cavity (lips, tongue, gum) followed by menorrhagia and epistaxis. ${ }^{106}$ Twenty percent of patients in the reproductive age had intraperitoneal bleeding at the time of ovulation, while $50 \%$ of pregnant women had at least one miscarriage. ${ }^{106}$

The clinical severity of FXIII deficiency prompts regular prophylaxis. ${ }^{98}$ This mode of treatment is facilitated by hemostatic levels of FXIII as low as 2 to $5 \%$; given the very long plasma half-life of infused FXIII (11-14 days), replacement material can be infused at large intervals (20-30 days). ${ }^{108}$ During pregnancies, monthly prophylactic infusions of FXIII concentrate are necessary to prevent abortions. There are two types of FXIII-containing products: a plasma-derived FXIII concentrate and a recombinant FXIII- $\mathrm{A}_{2}$ product. ${ }^{108,109}$ While the former is appropriate for patients with either $A$ or $B$ subunit deficiency, the recombinant FXIII- $A_{2}$ concentrate (which contains only the FXIII-A subunit) is only suitable for patients with 
FXIII-A subunit deficiency; however, this reflects the majority of such cases of this congenital bleeding disorder. ${ }^{110-112}$

\section{Anti-FXIII Alloantibodies}

Besides severe acquired FXIII deficiency caused by an autoantibody against either of the FXIII subunits, ${ }^{100}$ an anti-FXIII antibody may also develop in patients with inherited FXIII deficiency under replacement therapy. The incidence of such alloantibodies is unknown, although it seems to be a very rare event. Indeed, only seven cases of anti-FXIII-A alloantibodies have been reported so far in the literature, ${ }^{113-119}$ while there is only a single report on anti-FXIII-B alloantibodies. ${ }^{120}$ The most recent report was that published by Penzes and colleagues in 2016. ${ }^{119}$ The investigators characterized the anti-FXIII-A alloantibody, isolated from a patient with a severe FXIII-A deficiency and bleeding phenotype, demonstrating that it belonged to IgG class and exerted a multiple inhibitory effect on FXIII activation (interference with thrombin and $\mathrm{Ca}^{2+}$-induced FXIII activation) and activity (interference with the transglutaminase activity of activated FXIII). ${ }^{119}$ Also, the alloantibody was responsible for an accelerated clearance of administered plasma-derived FXIII concentrate from the circulation. Attempts to eliminate the alloantibody through ITI treatment (Malmö protocol including cyclophosphamide, IVIG, and high-dose FXIII) resulted only in a transient improvement, and the patients died due to intracerebral hemorrhage. ${ }^{119}$ Wada and colleagues ${ }^{120}$ reported the case of a patient with severe congenital FXIII-B deficiency, whose mild bleeding phenotype was aggravated by the development of an anti-FXIII-B alloantibody. Finally, in a multicenter phase III trial in 41 patients with congenital FXIII-A subunit deficiency treated with recombinant FXIII- $\mathrm{A}_{2}$ product, 4 patients developed transient, non-neutralizing, low-titer anti-FXIII antibodies. ${ }^{121}$

\section{Conclusion}

The development of inhibitory alloantibodies following replacement therapy in patients with inherited rare bleeding disorders is a very unusual adverse event, occurring much less frequently than reported in patients with congenital severe hemophilia A treated with FVIII concentrates, or even those with congenital severe hemophilia B treated with FIX concentrates. Nevertheless, the management of such rare inhibitors is perhaps even more challenging for caregivers of HTCs, especially considering that the published experience upon which to base their clinical practice is scanty. In this regard, while very little is known about treatments aiming to eliminate these inhibitors, rFVIIa seems to be the most universally acceptable therapeutic option for managing bleeding (except for FXIII deficiency, - Table 1). The implementation of international registries aimed at recording additional inhibitor cases and improving our knowledge on their management is greatly welcomed.

\section{References}

1 Franchini M, Mannucci PM. Hemophilia A in the third millennium. Blood Rev 2013;27(04):179-184
2 Mannucci PM, Mancuso ME, Franchini M. Tailoring hemostatic therapies to lower inhibitor development in previously untreated patients with severe hemophilia A. J Thromb Haemost 2016;14(07):1330-1336

3 Gringeri A, Mantovani LG, Scalone L, Mannucci PM; COCIS Study Group. Cost of care and quality of life for patients with hemophilia complicated by inhibitors: the COCIS Study Group. Blood 2003;102(07):2358-2363

4 Gringeri A, Mannucci PM; Italian Association of Haemophilia Centres. Italian guidelines for the diagnosis and treatment of patients with haemophilia and inhibitors. Haemophilia 2005;11 (06):611-619

5 Hay CR, Brown S, Collins PW, Keeling DM, Liesner R. The diagnosis and management of factor VIII and IX inhibitors: a guideline from the United Kingdom Haemophilia Centre Doctors Organisation. Br J Haematol 2006;133(06):591-605

6 Franchini M, Mannucci PM. Inhibitors of propagation of coagulation (factors VIII, IX and XI): a review of current therapeutic practice. Br J Clin Pharmacol 2011;72(04):553-562

7 Astermark J, Santagostino E, Keith Hoots W. Clinical issues in inhibitors. Haemophilia 2010;16(Suppl 5):54-60

8 Franchini M, Coppola A, Tagliaferri A, Lippi G. FEIBA versus NovoSeven in hemophilia patients with inhibitors. Semin Thromb Hemost 2013;39(07):772-778

9 Franchini M, Coppola A, Rocino A, et al; Italian Association of Haemophilia Centers AICE Working Group. Perceived challenges and attitudes to regimen and product selection from Italian haemophilia treaters: the 2013 AICE survey. Haemophilia 2014; 20(02):e128-e135

10 Franchini M, Mannucci PM. Alloantibodies in von Willebrand disease. Semin Thromb Hemost 2018. Current issue

11 Poon MC. Alloantibodies in Glanzmann Thrombasthenia and other inherited platelet disorders. Semin Thromb 2018. Current issue

12 Lippi G, Favaloro EJ, Montagnana M, Manzato F, Guidi GC Franchini M. Inherited and acquired factor V deficiency. Blood Coagul Fibrinolysis 2011;22(03):160-166

13 Giampaolo A, Vulcano F, Macioce G, et al. Factor-V expression in platelets from human megakaryocytic culture. $\mathrm{Br} \mathrm{J}$ Haematol 2005;128(01):108-111

14 Asselta R, Peyvandi F. Factor V deficiency. Semin Thromb Hemost 2009;35(04):382-389

15 Asselta R, Tenchini ML, Duga S. Inherited defects of coagulation factor V: the hemorrhagic side. J Thromb Haemost 2006;4(01):26-34

16 Vos HL. Inherited defects of coagulation factor V: the thrombotic side. J Thromb Haemost 2006;4(01):35-40

17 Thalji N, Camire RM. Parahemophilia: new insights into factor $\mathrm{v}$ deficiency. Semin Thromb Hemost 2013;39(06):607-612

18 Acharya SS, Coughlin A, Dimichele DM; North American Rare Bleeding Disorder Study Group. Rare Bleeding Disorder Registry: deficiencies of factors II, V, VII, X, XIII, fibrinogen and dysfibrinogenemias. J Thromb Haemost 2004;2(02):248-256

19 Makris M, Calizzani G, Fischer K, et al. The European Haemophilia Network (EUHANET). Blood Transfus 2014;12(Suppl 3): s515-s518

20 Guasch JF, Cannegieter S, Reitsma PH, van't Veer-Korthof ET, Bertina RM. Severe coagulation factor $V$ deficiency caused by a 4 bp deletion in the factor V gene. Br J Haematol 1998;101(01):32-39

21 Vos HL. An online database of mutations and polymorphisms in and around the coagulation factor $\mathrm{V}$ gene. J Thromb Haemost 2007;5(01):185-188

22 Peyvandi F, Bolton-Maggs PH, Batorova A, De Moerloose P. Rare bleeding disorders. Haemophilia 2012;18(Suppl 4):148-153

23 Murray JM, Rand MD, Egan JO, Murphy S, Kim HC, Mann KG. Factor V New Brunswick: Ala221-to-Val substitution results in reduced cofactor activity. Blood 1995;86(05):1820-1827

24 Franchini M, Lippi G. Acquired factor V inhibitors: a systematic review. J Thromb Thrombolysis 2011;31(04):449-457 
25 Lak M, Sharifian R, Peyvandi F, Mannucci PM. Symptoms of inherited factor $\mathrm{V}$ deficiency in 35 Iranian patients. Br J Haematol 1998;103(04):1067-1069

26 Peyvandi F, Di Michele D, Bolton-Maggs PHB, Lee CA, Tripodi A, Srivastava A; Project on Consensus Definitions in Rare Bleeeding Disorders of the Factor VIII/Factor IX Scientific and Standardisation Committee of the International Society on Thrombosis and Haemostasis. Classification of rare bleeding disorders (RBDs) based on the association between coagulant factor activity and clinical bleeding severity. J Thromb Haemost 2012;10(09):1938-1943

27 Duckers C, Simioni P, Rosing J, Castoldi E. Advances in understanding the bleeding diathesis in factor $\mathrm{V}$ deficiency. $\mathrm{Br} \mathrm{J}$ Haematol 2009;146(01):17-26

28 Di Paola J, Nugent D, Young G. Current therapy for rare factor deficiencies. Haemophilia 2001;7(Suppl 1):16-22

29 Peyvandi F, Duga S, Akhavan S, Mannucci PM. Rare coagulation deficiencies. Haemophilia 2002;8(03):308-321

30 Mumford AD, Ackroyd S, Alikhan R, et al; BCSH Committee. Guideline for the diagnosis and management of the rare coagulation disorders: a United Kingdom Haemophilia Centre Doctors' Organization guideline on behalf of the British Committee for Standards in Haematology. Br J Haematol 2014;167(03):304-326

31 Peyvandi F, Menegatti M. Treatment of rare factor deficiencies in 2016. Hematology (Am Soc Hematol Educ Program) 2016;2016 (01):663-669

32 Peyvandi F, Garagiola I, Biguzzi E. Advances in the treatment of bleeding disorders. J Thromb Haemost 2016;14(11):2095-2106

33 Cicchetti A, Berrino A, Casini $M$, et al. Health Technology Assessment of pathogen reduction technologies applied to plasma for clinical use. Blood Transfus 2016;14(04):287-386

34 Vaglio S, Prisco D, Biancofiore G, et al. Recommendations for the implementation of a Patient Blood Management programme. Application to elective major orthopaedic surgery in adults. Blood Transfus 2016;14(01):23-65

35 Mannucci PM, Peyvandi F, Franchini M. Rare inherited coagulation disorders other than hemophilia. In: White GC, Marder VJ, Aird WC, Bennet JS, Schulman S, eds. Hemostasis and Thrombosis. Basic Principles and Clinical Practice. Philadelphia, PA: Lippincott Williams and Wilkins; 2013

36 Fratantoni JC, Hilgartner M, Nachman RL. Nature of the defect in congenital factor $\mathrm{V}$ deficiency: study in a patient with an acquired circulating anticoagulant. Blood 1972;39(06):751-758

37 Mazzucconi MG, Solinas S, Chistolini A, Motta M, Mariani G. Inhibitor to factor $\mathrm{V}$ in severe factor $\mathrm{V}$ congenital deficiency. A case report. Nouv Rev Fr Hematol 1985;27(05):303-305

38 Salooja N, Martin P, Khair K, Liesner R, Hann I. Severe factor V deficiency and neonatal intracranial haemorrhage: a case report. Haemophilia 2000;6(01):44-46

39 Lee WS, Chong LA, Begum S, Abdullah WA, Koh MT, Lim EJ. Factor V inhibitor in neonatal intracranial hemorrhage secondary to severe congenital factor V deficiency. J Pediatr Hematol Oncol 2001;23 (04):244-246

40 Divanon F, Hecquard C, Borel-Derlon A. Experience with use of recombinant activated factor VII. J Clin Pharm Ther 2002;27(02): 133-138

41 Perez Botero J, Burns D, Thompson CA, Pruthi RK. Successful treatment with thalidomide of a patient with congenital factor $\mathrm{V}$ deficiency and factor $\mathrm{V}$ inhibitor with recurrent gastrointestinal bleeding from small bowel arteriovenous malformations. Haemophilia 2013;19(01):e59-e61

42 Bolton-Maggs PH, Perry DJ, Chalmers EA, et al. The rare coagulation disorders-review with guidelines for management from the United Kingdom Haemophilia Centre Doctors' Organisation. Haemophilia 2004;10(05):593-628

43 Lollar P. Pathogenic antibodies to coagulation factors. Part II. Fibrinogen, prothrombin, thrombin, factor V, factor XI, factor XII, factor XIII, the protein $C$ system and von Willebrand factor. J Thromb Haemost 2005;3(07):1385-1391
44 Ang AL, Kuperan P, Ng CH, Ng HJ. Acquired factor V inhibitor. A problem-based systematic review. Thromb Haemost 2009;101 (05):852-859

45 Knöbl P, Lechner K. Acquired factor V inhibitors. Baillieres Clin Haematol 1998;11(02):305-318

46 Chediak J, Ashenhurst JB, Garlick I, Desser RK. Successful management of bleeding in a patient with factor $\mathrm{V}$ inhibitor by platelet transfusions. Blood 1980;56(05):835-841

47 Gavva C, Yates SG, Rambally S, Sarode R. Transfusion management of factor $V$ deficiency: three case reports and review of the literature. Transfusion 2016;56(07):1745-1749

48 Ragni MV, Lewis JH, Spero JA, Hasiba U. Factor VII deficiency. Am J Hematol 1981;10(01):79-88

49 Mariani G, Bernardi F. Factor VII Deficiency. Semin Thromb Hemost 2009;35(04):400-406

50 van 't Hooft FM, Silveira A, Tornvall P, et al. Two common functional polymorphisms in the promoter region of the coagulation factor VII gene determining plasma factor VII activity and mass concentration. Blood 1999;93(10):3432-3441

51 Triplett DA, Brandt JT, Batard MA, Dixon JL, Fair DS. Hereditary factor VII deficiency: heterogeneity defined by combined functional and immunochemical analysis. Blood 1985;66(06):1284-1287

52 McVey JH, Boswell E, Mumford AD, Kemball-Cook G, Tuddenham EG. Factor VII deficiency and the FVII mutation database. Hum Mutat 2001;17(01):3-17

53 Mariani G, Herrmann FH, Dolce A, et al; International Factor VII Deficiency Study Group. Clinical phenotypes and factor VII genotype in congenital factor VII deficiency. Thromb Haemost 2005;93(03):481-487

54 Peyvandi F, Garagiola I, Palla R, Marziliano N, Mannucci PM. Role of the 2 adenine (g.11293_11294insAA) insertion polymorphism in the $3^{\prime}$ untranslated region of the factor VII (FVII) gene: molecular characterization of a patient with severe FVII deficiency. Hum Mutat 2005;26(05):455-461

55 Peyvandi F, Jenkins PV, Mannucci PM, et al. Molecular characterisation and three-dimensional structural analysis of mutations in 21 unrelated families with inherited factor VII deficiency. Thromb Haemost 2000;84(02):250-257

56 Giansily-Blaizot M, Aguilar-Martinez P, Biron-Andreani C, Jeanjean P, Igual H, Schved JF; Study Group of Factor Seven Deficiency. Analysis of the genotypes and phenotypes of 37 unrelated patients with inherited factor VII deficiency. Eur J Hum Genet 2001;9(02):105-112

57 Di Minno MN, Dolce A, Mariani G; STER Study Group. Bleeding symptoms at disease presentation and prediction of ensuing bleeding in inherited FVII deficiency. Thromb Haemost 2013;109 (06):1051-1059

58 Quintavalle G, Riccardi F, Rivolta GF, et al; Ad-Hoc Study Group. F7 gene variants modulate protein levels in a large cohort of patients with factor VII deficiency. Results from a genotypephenotype study. Thromb Haemost 2017;117(08):1455-1464

59 Herrmann FH, Wulff K, Auerswald G, et al; Greifswald Factor FVII Deficiency Study Group. Factor VII deficiency: clinical manifestation of 717 subjects from Europe and Latin America with mutations in the factor 7 gene. Haemophilia 2009;15(01):267-280

60 Peyvandi F, Mannucci PM, Asti D, Abdoullahi M, DI Rocco N, Sharifian R. Clinical manifestations in 28 Italian and Iranian patients with severe factor VII deficiency. Haemophilia 1997;3 (04):242-246

61 Marty S, Barro C, Chatelain B, et al. The paradoxical association between inherited factor VII deficiency and venous thrombosis. Haemophilia 2008;14(03):564-570

62 Franchini M, Lippi G. Recombinant activated factor VII: mechanisms of action and current indications. Semin Thromb Hemost 2010;36(05):485-492

63 Mariani G, Konkle BA, Ingerslev J. Congenital factor VII deficiency: therapy with recombinant activated factor VII - a critical appraisal. Haemophilia 2006;12(01):19-27 
64 Mariani G, Dolce A, Batorova A, et al; STER and the International Factor VII Deficiency Study Groups. Recombinant, activated factor VII for surgery in factor VII deficiency: a prospective evaluation the surgical STER. Br J Haematol 2011;152(03):340-346

65 Nicolaisen EM, Hansen LL, Poulsen F, Glazer S, Hedner U. Immunological aspects of recombinant factor VIIa (rFVIIa) in clinical use. Thromb Haemost 1996;76(02):200-204

66 Ingerslev J, Christiansen K, Sørensen B; International Registry on Factor VII Deficiency (IRF7) Steering Committee. Inhibitor to factor VII in severe factor VII deficiency: detection and course of the inhibitory response. J Thromb Haemost 2005;3(04):799-800

67 Pruthi RK, Rodriguez V, Allen C, Slaby JA, Schmidt KA, Plumhoff EA. Molecular analysis in a patient with severe factor VII deficiency and an inhibitor: report of a novel mutation (S103G). Eur J Haematol 2007;79(04):354-359

68 Tokgoz H, Caliskan U, Lavigne-Lissalde G, Giansily-Blaizot M. Successful prophylactic use of recombinant activated factor VII (rFVIIa) in a patient with congenital FVII deficiency and inhibitors to FVII. Haemophilia 2012;18(01):e25-e27

69 Mariani G, Napolitano M, Dolce A, et al; Seven Treatment Evaluation Registry; International Factor VII Deficiency Study Group. Replacement therapy for bleeding episodes in factor VII deficiency. A prospective evaluation. Thromb Haemost 2013;109 (02):238-247

70 Batorova A, Mariani G, Kavakli K, et al; STER Study Group. Inhibitors to factor VII in congenital factor VII deficiency. Haemophilia 2014;20(02):e188-e191

71 Borhany M, Delbes C, Giansily-Blaizot M, et al. A new report of FVII-inhibitor in a patient suffering from severe congenital FVII deficiency. Haemophilia 2015;21(04):e336-e338

72 See WS, Chang KO, Cheuk DK, et al. Inhibitor development after liver transplantation in congenital factor VII deficiency. Haemophilia 2016;22(05):e417-e422

73 Duga S, Salomon O. Factor XI Deficiency. Semin Thromb Hemost 2009;35(04):416-425

74 Franchini M, Veneri D, Lippi G. Inherited factor XI deficiency: a concise review. Hematology 2006;11(05):307-309

75 Seligsohn U. Factor XI deficiency in humans. J Thromb Haemost 2009;7(Suppl 1):84-87

76 James P, Salomon O, Mikovic D, Peyvandi F. Rare bleeding disorders - bleeding assessment tools, laboratory aspects and phenotype and therapy of FXI deficiency. Haemophilia 2014;20 (Suppl 4):71-75

77 Asakai R, Chung DW, Davie EW, Seligsohn U. Factor XI deficiency in Ashkenazi Jews in Israel. N Engl J Med 1991;325(03):153-158

78 Mitchell M, Mountford R, Butler R, et al. Spectrum of factor XI (F11) mutations in the UK population-116 index cases and 140 mutations. Hum Mutat 2006;27(08):829

79 Soldà G, Asselta R, Ghiotto R, Tenchini ML, Castaman G, Duga S. A type II mutation (Glu117stop), induction of allele-specific mRNA degradation and factor XI deficiency. Haematologica 2005;90(12):1716-1718

80 Zadra G, Asselta R, Tenchini ML, et al. Simultaneous genotyping of coagulation factor XI type II and type III mutations by multiplex real-time polymerase chain reaction to determine their prevalence in healthy and factor XI-deficient Italians. Haematologica 2008;93(05):715-721

81 Salomon O, Steinberg DM, Seligshon U. Variable bleeding manifestations characterize different types of surgery in patients with severe factor XI deficiency enabling parsimonious use of replacement therapy. Haemophilia 2006;12(05):490-493

82 Peyvandi F, Lak M, Mannucci PM. Factor XI deficiency in Iranians: its clinical manifestations in comparison with those of classic hemophilia. Haematologica 2002;87(05):512-514

83 Myers B, Pavord S, Kean L, Hill M, Dolan G. Pregnancy outcome in Factor XI deficiency: incidence of miscarriage, antenatal and postnatal haemorrhage in 33 women with Factor XI deficiency. BJOG 2007;114(05):643-646
84 Salomon O, Steinberg DM, Tamarin I, Zivelin A, Seligsohn U. Plasma replacement therapy during labor is not mandatory for women with severe factor XI deficiency. Blood Coagul Fibrinolysis 2005;16(01):37-41

85 Santagostino E, Mancuso ME, Morfini M, et al. Solvent/detergent plasma for prevention of bleeding in recessively inherited coagulation disorders: dosing, pharmacokinetics and clinical efficacy. Haematologica 2006;91(05):634-639

86 Salomon O, Zivelin A, Livnat T, Seligsohn U. Inhibitors to Factor XI in patients with severe Factor XI deficiency. Semin Hematol 2006;43(01, Suppl 1):S10-S12

87 Zucker M, Zivelin A, Teitel J, Seligsohn U. Induction of an inhibitor antibody to factor XI in a patient with severe inherited factor XI deficiency by Rh immune globulin. Blood 2008;111(03):1306-1308

88 Salomon O, Zivelin A, Livnat T, et al. Prevalence, causes, and characterization of factor XI inhibitors in patients with inherited factor XI deficiency. Blood 2003;101(12):4783-4788

89 Hedner U. Factor VIIa in the treatment of haemophilia. Blood Coagul Fibrinolysis 1990;1(03):307-317

90 Billon S, Le Niger C, Escoffre-Barbe M, Vicariot M, Abgrall JF. The use of recombinant factor VIIa (NovoSeven) in a patient with a factor XI deficiency and a circulating anticoagulant. Blood Coagul Fibrinolysis 2001;12(07):551-553

91 Lawler P, White B, Pye S, et al. Successful use of recombinant factor VIIa in a patient with inhibitor secondary to severe factor XI deficiency. Haemophilia 2002;8(02):145-148

92 Bern MM, Sahud M, Zhukov O, Qu K, Mitchell W Jr. Treatment of factor XI inhibitor using recombinant activated factor VIIa. Haemophilia 2005;11(01):20-25

93 Salomon O, Steinberg DM, Dardik R, et al. Inherited factor XI deficiency confers no protection against acute myocardial infarction. J Thromb Haemost 2003;1(04):658-661

94 Livnat T, Zivelin A, Martinowitz U, Salomon O, Seligsohn U. Prerequisites for recombinant factor VIIa-induced thrombin generation in plasmas deficient in factors VIII, IX or XI. J Thromb Haemost 2006;4(01):192-200

95 Livnat T, Tamarin I, Mor Y, et al. Recombinant activated factor VII and tranexamic acid are haemostatically effective during major surgery in factor XI-deficient patients with inhibitor antibodies. Thromb Haemost 2009;102(03):487-492

96 Kenet G, Lubetsky A, Luboshitz J, et al. Lower doses of rFVIIa therapy are safe and effective for surgical interventions in patients with severe FXI deficiency and inhibitors. Haemophilia 2009;15(05):1065-1073

97 Teruya J, Styler M. Management of factor XI inhibitor for cardiac intervention: successful treatment with immunosuppressive therapy and plasma exchange. Haemophilia 2000;6(03):158-161

98 Levy JH, Greenberg C. Biology of Factor XIII and clinical manifestations of Factor XIII deficiency. Transfusion 2013;53(05): $1120-1131$

99 Dorgalaleh A, Rashidpanah J. Blood coagulation factor XIII and factor XIII deficiency. Blood Rev 2016;30(06):461-475

100 Karimi M, Bereczky Z, Cohan N, Muszbek L. Factor XIII Deficiency. Semin Thromb Hemost 2009;35(04):426-438

101 Ichinose A. Physiopathology and regulation of factor XIII. Thromb Haemost 2001;86(01):57-65

102 Katona E, Haramura G, Kárpáti L, Fachet J, Muszbek L. A simple, quick one-step ELISA assay for the determination of complex plasma factor XIII (A2B2). Thromb Haemost 2000;83(02):268-273

103 Ivaskevicius V, Seitz R, Kohler HP, et al; Study Group. International registry on factor XIII deficiency: a basis formed mostly on European data. Thromb Haemost 2007;97(06):914-921

104 Anwar R, Miloszewski KJ. Factor XIII deficiency. Br J Haematol 1999;107(03):468-484

105 Lauer P, Metzner HJ, Zettlmeissl G, et al. Targeted inactivation of the mouse locus encoding coagulation factor XIII-A: hemostatic abnormalities in mutant mice and characterization of the coagulation deficit. Thromb Haemost 2002;88(06):967-974 
106 Lak M, Peyvandi F, Ali Sharifian A, Karimi K, Mannucci PM. Pattern of symptoms in 93 Iranian patients with severe factor XIII deficiency. J Thromb Haemost 2003;1(08):1852-1853

107 Biswas A, Ivaskevicius V, Thomas A, Oldenburg J. Coagulation factor XIII deficiency. Diagnosis, prevalence and management of inherited and acquired forms. Hamostaseologie 2014;34(02):160-166

108 Gootenberg JE. Factor concentrates for the treatment of factor XIII deficiency. Curr Opin Hematol 1998;5(06):372-375

109 Lovejoy AE, Reynolds TC, Visich JE, et al. Safety and pharmacokinetics of recombinant factor XIII-A2 administration in patients with congenital factor XIII deficiency. Blood 2006;108(01):57-62

110 Muszbek L, Katona É. Diagnosis and management of congenital and acquired FXIII deficiencies. Semin Thromb Hemost 2016;42 (04):429-439

111 Lassila R. Clinical use of factor XIII concentrates. Semin Thromb Hemost 2016;42(04):440-444

112 Carcao M, Fukutake K, Inbal A, et al. Developing the first recombinant factor XIII for congenital factor XIII deficiency: clinical challenges and successes. Semin Thromb Hemost 2017;43(01):59-68

113 Lorand L, Urayama T, De Kiewiet JW, Nossel HL. Diagnostic and genetic studies on fibrin-stabilizing factor with a new assay based on amine incorporation. J Clin Invest 1969;48(06):1054-1064

114 Godal HC. An inhibitor to fibrin stabilizing factor (FSF, factor XIII). Scand J Haematol 1970;7(01):43-48
115 Godal HC, Ly B. An inhibitor of activated factor XIII, inhibiting fibrin cross-linking but not incorporation of amine into casein. Scand J Haematol 1977;19(05):443-448

116 Henriksson P, McDonagh J, Villa M. Type I autoimmune inhibitor of factor XIII in a patient with congenital factor XIII deficiency [abstract]. Thromb Haemost 1983;50:272

117 Seiving B, Henriksson P, Stenberg P, Nilsson IM. A reversed activity staining procedure for detection of an acquired antibody against factor XIII in a girl with factor XIII deficiency. Br J Haematol 1992;82(02):414-416

118 Rivard GE, St Louis J, Lacroix S, Champagne M, Rock G. Immunoadsorption for coagulation factor inhibitors: a retrospective critical appraisal of 10 consecutive cases from a single institution. Haemophilia 2003;9(06):711-716

119 Pénzes K, Vezina C, Bereczky Z, et al. Alloantibody developed in a factor XIII A subunit deficient patient during substitution therapy; characterization of the antibody. Haemophilia 2015; 22:268-275

120 Wada H, Souri M, Matsumoto R, Sugihara T, Ichinose A. Alloantibodies against the B subunit of plasma factor XIII developed in its congenital deficiency. Thromb Haemost 2013;109(04):661-668

121 Inbal A, Oldenburg J, Carcao M, Rosholm A, Tehranchi R, Nugent D. Recombinant factor XIII: a safe and novel treatment for congenital factor XIII deficiency. Blood 2012;119(22):5111-5117
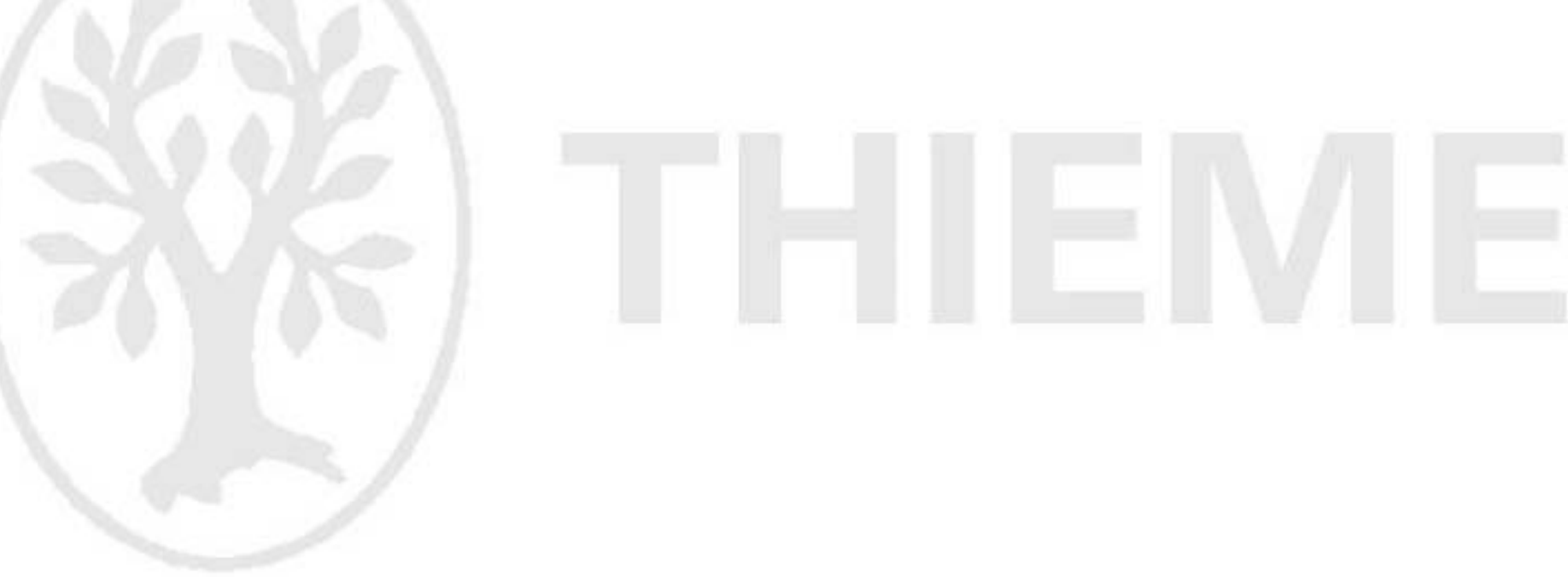